\title{
Motor performance of children with attention deficit hyperactivity disorder: focus on the Bruininks-Oseretsky Test of Motor Proficiency
}

\author{
Khushboo Prashant Adhvaryu, $\mathrm{PT}^{1}$, Suruliraj Karthikbabu, $\mathrm{PhD}^{2}$, Pratiksha Tilak Rao, PhD ${ }^{2}$ \\ ${ }^{1}$ Paediatric Physiotherapy Postgraduate, MAHE, MCHP, Bangalore, India; ${ }^{2}$ Department of Physiotherapy, MAHE, MCHP, Bangalore, India
}

The literature review aimed to analyze studies assessing the motor abilities of children with attention deficit hyperactivity disorder (ADHD) using the Bruininks-Oseretsky Test of Motor Proficiency (BOTMP). The PubMed, OVID, Cochrane, and PEDro databases were searched for relevant articles published between February 2003 and September 2021. Despite the retrieval of limited studies, most included in this review were of fair to good quality. The diagnostic criteria for ADHD adhered to Diagnostic and Statistical Manual of Mental Disorders standards. The BOTMP has been used diversely in various countries, has been translated into various languages, is administered by various qualified medical professionals on children with variants of $\mathrm{ADHD}$, with the long form of the tool used more widely than its short form. The motor performance of children with ADHD was better than that of children with other developmental disorders, but children with ADHD underperformed compared to their age-matched typically developing peers. Although the BOTMP tool has been widely used to evaluate the motor performance of children with various disabilities, our understanding of the motor repertoire of children with ADHD is inadequate. Future research can aim to use the BOTMP to better understand the motor repertoire of children with ADHD to aid their overall rehabilitation.

Key words: Bruininks-Oseretsky Test of Motor Proficiency, BOTMP, BOT-2, ADHD, ADD

\section{Key message}

- Children with attention deficit hyperactivity disorder (ADHD) tend to have impaired motor performance that may affect their growth and development.

- Although widely used among children with developmental disorders, the Bruininks-Oseretsky Test of Motor Proficiency (BOTMP) is used sparsely among children with ADHD.

- Assessment by the BOTMP increases our understanding of the motor repertoire of children with ADHD.
- Wider usage of the BOTMP will enable more comprehensive planning of rehabilitation goals to enhance the motor abilities of children with ADHD.

\section{Introduction}

Attention deficit hyperactivity disorder (ADHD) is a behavioral disorder characterized by impaired cognition, impulsivity, a short attention span, excitability, irritability, fidgeting behavior, persistent repetition of words, lacking ability to express oneself, etc. ${ }^{1)} \mathrm{ADHD}$ is a chronic condition that manifests in childhood and persists into adulthood unless detected early. Children with ADHD tend to have delayed motor development compared to their peers. ${ }^{1)}$ The worldwide prevalence of ADHD is estimated at $2.2 \%$ in adolescents less than 18 years of age. ${ }^{1)}$

Children with ADHD are categorized as follows: ADHD with inattentiveness (ADHD I); ADHD with hyperactivity (ADHD$\mathrm{H})$; and combined type (ADHD-C), which most affected children tend to have. ${ }^{2)}$ Children with ADHD may also have developmental coordination disorder (DCD); in fact, there is an estimated 50\% overlap between the 2 disorders. ${ }^{3,4)}$ This overlap results into a superimposition of symptoms that leads to motor weakness. According to the American Psychiatric Association, DCD is a lack of coordination between one's mental intentions and the body's ability to perform them. ${ }^{3}$ Whether the impaired motor performance of children with ADHD is due to the underlying comorbidity of DCD or independent occurrence of ADHD remains unclear. DCD symptoms like coordination and balance issues interfere with an individual's daily life, involve constant tripping and falling, impact leisure and play, and usually appear in the early developmental stages. ${ }^{2,4)}$ Moreover, children with ADHD also commonly have various neurodevelopmental, behavioral, and learning disorders such as autism spectrum disorder (ASD), sensory processing disorders, reading disability (RD), oppositional defiance disorder (ODD), and dyslexia.

\footnotetext{
Corresponding author: Pratiksha Tilak Rao, PhD, Department of Physiotherapy, MCHP, MAHE, Manipal Hospital, HAL Old airport road, Bangalore-560017, Karnataka, India 


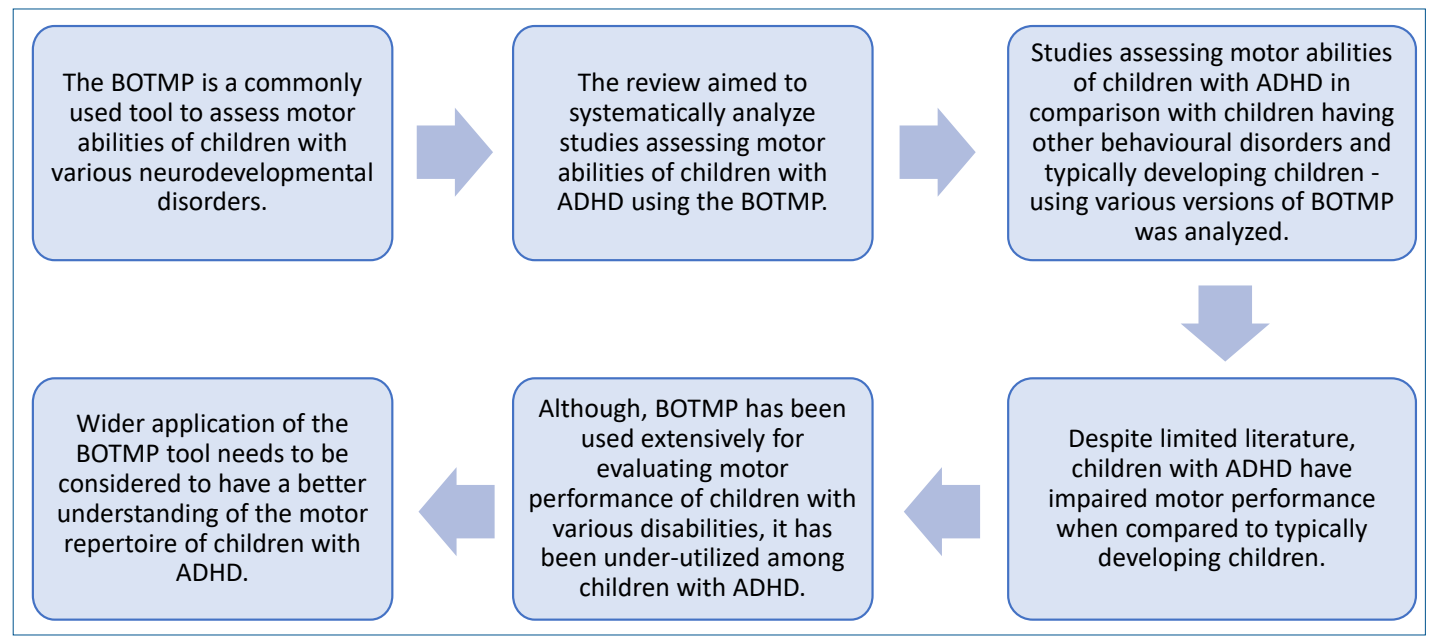

Graphical abstract. BOTMP, Bruininks-Oseretsky Test of Motor Proficiency; ADHD, attention deficit hyperactivity disorder.

Learning disorders often go unnoticed due to the hyperactivity noted during the crucial developmental years. ${ }^{5)}$

The literature states that the motor performance of children with ADHD-H was better than those of the other 2 categories. ${ }^{4)}$ This was purely found using assessments other than the BruininksOseretsky Test of Motor Proficiency (BOTMP). ${ }^{6}$ Causes of poor motor skills in children with ADHD can be related to various hypotheses: (1) Associated comorbidities in children with ADHD can superimpose motor deficits; (2) Deficits in motor performance are primarily due to impaired attention and focus; and (3) These children have a lack of inhibition that accounts for a delayed development of motor skills. ${ }^{4)}$

The persistent inefficiency of children with ADHD at performing activities of daily living due to their motor dysfunction has led to the need for motor assessment tools and assessments of their overall motor performance to comprehensively understand their motor abilities. ${ }^{7)}$ Several standardized tools have been used to assess the motor performance of children with ADHD, namely the Motor Assessment Battery for Children (MABC), Peabody Developmental Motor Scales, and BOTMP. ${ }^{6}$ These tools have been preferred over others because of their good psychometric properties, clear and simple explanation, wide age range, inclusion of subtests that thoroughly assess overall motor proficiency, and detailed scoring. $\left.{ }^{6}\right)$

Among these tools, the BOTMP comprehensively assesses the motor abilities of children with all developmental disorders. $\left.{ }^{6}\right)$ Since the motor performance of children with ADHD has not been adequately explored using the BOTMP as an outcome measure, an assessment of the extent of its usage among children with ADHD. Therefore, here we aimed to examine usage of the BOTMP to assess the motor abilities of children with ADHD.

\section{Methods}

\section{Search strategy}

We searched the PubMed, Cochrane, OVID, and PEDro databases for relevant articles published between February 2003 and September 2021. The keywords used are given in Supple. mentary Table 1 . An additional search performed for unpublished data yielded no results.

\section{Study selection and eligibility criteria}

After the removal of duplicates from the records obtained from all 4 databases, all retrieved articles were subjected to title and abstract screening, followed by full-text screening based on the eligibility criteria. Studies were included in the review if they met the following criteria: inclusion of children diagnosed with ADHD by Diagnostic and Statistical Manual of Mental Disorders (DSM) criteria or American Psychiatric Association criteria by a pediatrician; use of one or more components of the BOTMP/ BOT-2; participants aged 4-21 years; comorbid DCD, ODD, or destructive behavioral disorder (DBD); inclusion of all variants of $\mathrm{ADHD}$; and observational or interventional study design of children with ADHD published until September 2021. Studies were excluded if they did not include children with ADHD or use the BOTMP as the outcome measure. The title and abstract and full-text screenings were performed independently by 2 reviewers, wherein any discrepancies were discussed with a third reviewer until consensus was reached.

\section{Data extraction}

The data extraction process was performed independently by 2 reviewers and cross-checked by the third reviewer in cases of discrepancies. Information extracted from the studies included: publication details, author names, year of publication, study design, BOTMP/BOT-2 long form (LF)/short form (SF)/any subtest used, other scales used if any to measure motor performance, ADHD type, participant ages, diagnostic criteria for $\mathrm{ADHD}$, results of motor outcome measures including BOTMP/ 
Table 1. General characteristics of the studies

\begin{tabular}{|c|c|c|c|c|c|c|}
\hline Study & Country & $\begin{array}{l}\text { Diagnostic } \\
\text { criteria }\end{array}$ & $\begin{array}{l}\text { Age } \\
(y r)\end{array}$ & Sample size & Children other than ADHD & Type of tool \\
\hline $\begin{array}{l}\text { Rigby et al.., } \\
2020\end{array}$ & USA & DSM-5 & $5-16$ & ADHD, 9; total, 31; neurodevelopmental disorders, 16 & $\begin{array}{l}\text { Autism spectrum disorder, learn- } \\
\text { ing disability, motor delay }\end{array}$ & BOT-2 SF \\
\hline $\begin{array}{l}\text { Mancini et al.., } \\
2020\end{array}$ & Australia & DSM-5 & $6-14$ & Boys, 78; girls, 6; total, 84 & None & $\begin{array}{l}\text { BOT-2 LF and } \\
\text { BOT-2 SF }\end{array}$ \\
\hline $\begin{array}{l}\text { Cak et al.., } \\
2018\end{array}$ & Turkey & DSM-4 & $8-11$ & ADHD, 38; controls, 20; total, 58 & $\begin{array}{l}\text { Age and gender matched con- } \\
\text { trols }\end{array}$ & BOTMP LF \\
\hline $\begin{array}{l}\text { Soleimani et } \\
\text { al., }{ }^{22)} 2017\end{array}$ & Iran & DSM-4 & $6-12$ & Boys, 11; girls, 5; total, 16 & None & BOT-2 SF \\
\hline $\begin{array}{l}\text { Van Damme et } \\
\text { al., }^{10)} 2015\end{array}$ & Belgium & DSM-4 & $12-18$ & $\begin{array}{l}\text { Oppositional defiant disorder, 36; disruptive conduct } \\
\text { disorder, 63; behavior disorder, 99; disruptive } \\
\text { behavior disorder and ADHD, 53; disruptive behavior } \\
\text { disorder-ADHD, 46; controls, } 87\end{array}$ & $\begin{array}{l}\text { Disruptive behavior disorder, age } \\
\text { and gender matched controls }\end{array}$ & BOT-2 LF \\
\hline $\begin{array}{l}\text { Jang et al., } \\
2015\end{array}$ & Korea & DSM-4 & $6-13$ & Boys, 17; girl, 1; total, 18 & None & BOT-2 LF \\
\hline $\begin{array}{l}\text { Mao et al., } \\
2014\end{array}$ & Taiwan & DSM-4 & $6-12$ & Boys, 18; girls, 2; total, 20; controls, 20 & $\begin{array}{l}\text { Age and gender matched con- } \\
\text { trols }\end{array}$ & $\begin{array}{l}\text { BOTMP } \\
\text { balance } \\
\text { subtest }\end{array}$ \\
\hline $\begin{array}{l}\text { Poblano et al.., } \\
2014\end{array}$ & Mexico & DSM-4 & $7-12$ & ADHD, 19; boys, 16; girls, 3; controls, 19 & $\begin{array}{l}\text { Age and gender matched con- } \\
\text { trols }\end{array}$ & BOTMP LF \\
\hline $\begin{array}{l}\text { Gharebaghy et } \\
\text { al., } 2014\end{array}$ & Iran & Pediatrician & $7-12$ & Boys, 5; girl, 1 ; total, 6 & None & BOTMP LF \\
\hline $\begin{array}{l}\text { Cho et al.,.9) } \\
2013\end{array}$ & Korea & DSM-4 & & $\begin{array}{l}\text { Boys, 51; girls, 7; total, 58; controls, 70; boys, 56; girls, } \\
14\end{array}$ & $\begin{array}{l}\text { Age and gender matched con- } \\
\text { trols }\end{array}$ & BOT-2 LF \\
\hline $\begin{array}{l}\text { Tseng et al., } \\
2004\end{array}$ & Taiwan & DSM & $6-11$ & Boys, 36; girls, 6; total, 42; controls, 42 & None & BOTMP LF \\
\hline $\begin{array}{l}\text { Dewey et al., } \\
2007\end{array}$ & Canada & DSM-4 & $5-18$ & $\begin{array}{l}\text { Autism spectrum disorder, 49; coordination disorder, } \\
\text { 46; development coordination disorder and ADHD, } \\
\text { 38; ADHD, } 27 \text { controls, } 78\end{array}$ & $\begin{array}{l}\text { Autism spectrum disorders, de- } \\
\text { velopmental coordination dis- } \\
\text { order, age and gender matched } \\
\text { controls }\end{array}$ & BOTMP SF \\
\hline $\begin{array}{l}\text { Kooistra et al., }{ }^{2)} \\
2005\end{array}$ & Canada & DSM-3 & $8-16$ & $\begin{array}{l}\text { ADHD,29; reading disability, 63; ADHD and reading } \\
\text { disability, 47; ADHD and oppositional defiant disorder, } \\
\text { 19; oppositional defiant disorder, } 21 \text {; controls, } 112\end{array}$ & $\begin{array}{l}\text { Reading disability, oppositional } \\
\text { defiant disorder, age and } \\
\text { gender matched controls }\end{array}$ & BOTMP LF \\
\hline $\begin{array}{l}\text { Dewey et al., } \\
2003\end{array}$ & Australia & DSM-3 & $8-16$ & $\begin{array}{l}\text { Reading disability, } 60 \text {; boys, 39; girls, 19; ADHD, 49; } \\
\text { boys, 44; girls, 5; ADHD and reading disability, 50; } \\
\text { boys, 38; girls, } 12\end{array}$ & Reading disability & BOTMP SF \\
\hline
\end{tabular}

DSM, Diagnostic and Statistical Manual of Mental Disorders; ADHD, attention deficit hyperactivity disorder; BOTMP, Bruininks-Oseretsky Test of Motor Proficiency; SF, short form; LF, long form; BOT-2, Bruininks-Oseretsky Test of Motor Proficiency Second Edition.

BOT-2, sample size, participant sex, and inclusion of children without ADHD or typically developing children.

\section{Quality assessment of included studies}

Although the included studies had different study designs, most were cross-sectional observational studies. The Downs and Black Quality Assessment checklist and the National Heart, Lung, and Blood Institute (NIH) tool, which enable the objective assessment of all components of various study designs, were used to evaluate all of the included studies. Two reviewers separately performed the quality assessments, and discrepancies were resolved by discussion until consensus was reached.

\section{Results}

\section{Description of studies}

The literature search identified 86 studies, of which 14 met the eligibility criteria (Fig. 1). The included studies were published between February 2003 and September 2021 and conducted in Canada, Australia, Iran, Korea, Turkey, Mexico, Taiwan, the USA, and Belgium. The studies used various study designs i.e. cross-sectional observational $(n=10)$, interventional $(n=3)$, and randomized controlled trial (RCT; $n=1)$. General characteristics of the studies such as ADHD, participant age and sex, the inclusion of children without $\mathrm{ADHD}$, and assessment tool type used (LF or SF of the BOTMP/BOT-2) are described in Table 1.

\section{Quality assessment}

According to the Downs and Black Quality Assessment tool (Table 2), 5 studies included in this review were of good quality, 8 were of fair quality, and 1 was of poor quality. The 5 good quality studies scored fairly well in all components of the Downs and Black Quality Assessment, mentioning adequate information about the methods, sampling, blinding, and results. Eight studies with fair quality scored well in the reporting, internal, and 


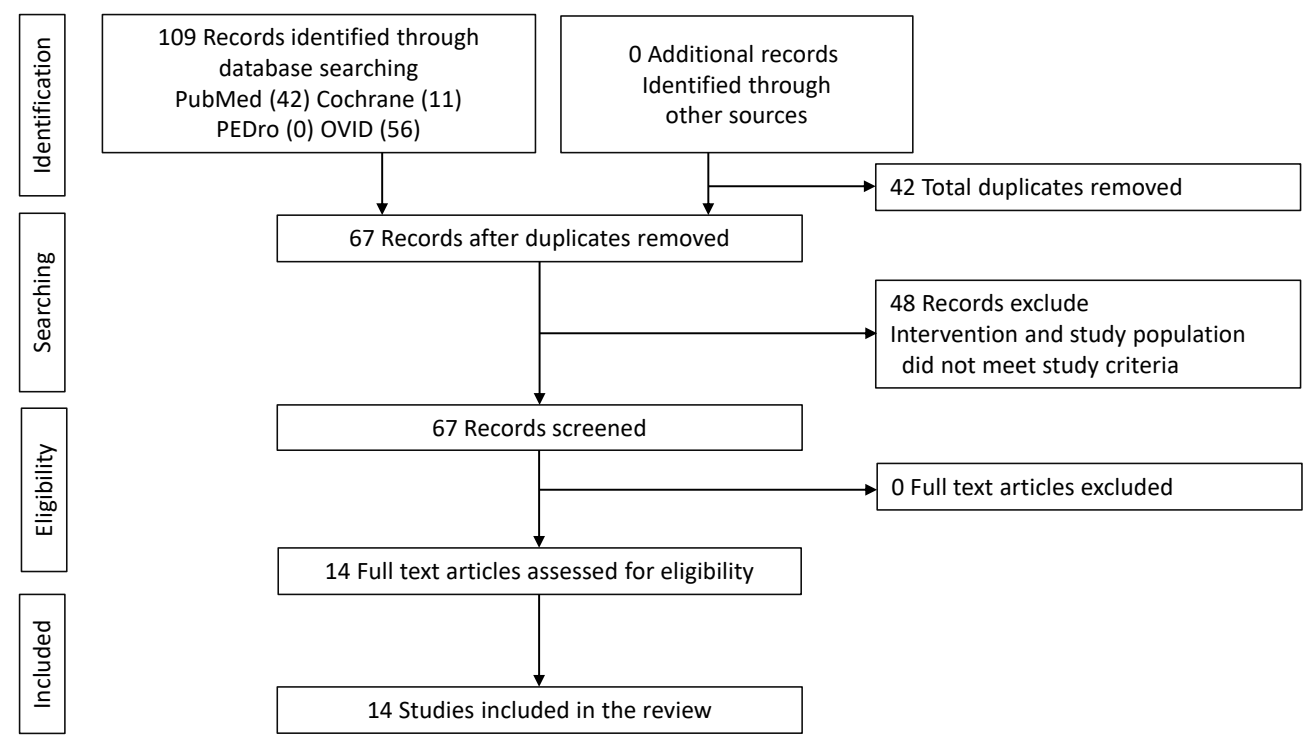

Fig. 1. PRISMA (Preferred Reporting Items for Systematic Reviews and Meta-Analyses) flow chart.

Table 2. Downs and Black Quality Assessment of the included studies

\begin{tabular}{|c|c|c|c|c|c|}
\hline Study & Reporting (10) & External validity (3) & Internal validity (7) & Confounding (6) & Power (2) \\
\hline Rigby et al., ${ }^{17)} 2020$ & 9 & 1 & 6 & 3 & 2 \\
\hline Mancini et al., ${ }^{15)} 2020$ & 7 & 2 & 5 & 2 & 0 \\
\hline Cak et al.. ${ }^{8)} 2018$ & 9 & 0 & 5 & 3 & 0 \\
\hline Soleimani et al., ${ }^{22)} 2017$ & 9 & 1 & 7 & 5 & 2 \\
\hline Damme et al.., ${ }^{10)} 2015$ & 8 & 3 & 5 & 2 & 2 \\
\hline Jang et al., ${ }^{14)} 2015$ & 8 & 1 & 5 & 3 & 0 \\
\hline Mao et al., ${ }^{7)} 2014$ & 7 & 1 & 5 & 3 & 0 \\
\hline Poblano et al., ${ }^{20)} 2014$ & 6 & 0 & 5 & 2 & 0 \\
\hline Gharebaghy et al., 2014 & 6 & 1 & 6 & 3 & 0 \\
\hline Cho et al.., 2013 & 8 & 0 & 5 & 2 & 0 \\
\hline Dewey et al.,, 2007 & 6 & 1 & 6 & 1 & 0 \\
\hline Kooistra et al., ${ }^{2)} 2005$ & 7 & 3 & 6 & 4 & 0 \\
\hline Tseng et al.,. 27$) 2004$ & 8 & 2 & 5 & 3 & 0 \\
\hline Dewey et al., ${ }^{18)} 2003$ & 8 & 3 & 7 & 4 & 0 \\
\hline
\end{tabular}

external validity components and scored low in confounding and power components. The other study scored well in the internal and external validity components but not well in other components of the Downs and Black Quality Assessment, displaying an overall poor performance on the quality assessment. According to the NIH quality assessment (Table 3), 7 studies were rated as good and the rest were rated as fair. Studies were rated fair overall as their sample sizes were not sufficiently large to provide confidence in their findings, and blinding was not adequately reported. Studies that were graded as good justified their sample size calculations and blinding.

\section{Countries}

The included studies were conducted in Canada $(n=2)$, Australia $(n=2)$, Iran $(n=2)$, Korea $(n=2)$, Turkey $(n=1)$, Mexico $(n=1)$, Taiwan $(n=2), \operatorname{USA}(n=1)$, and Belgium $(n=1)$.

\section{Diagnostic criteria}

All studies mentioned their criteria of including children diagnosed with ADHD by the DSM American Psychiatric Association third, fourth, and fifth editions except for one study that included children diagnosed with $\mathrm{ADHD}$ by a pediatrician. ${ }^{5)}$

\section{Age and sex}

Studies included participants aged 5-18 years of age. The performance of children with ADHD was not at par with their age-matched normative values given in the BOTMP.,8-17) None of the studies mentioned age-wise differences in motor performance of children with ADHD as described in the BOTMP and BOT-2 manual. All studies generalized the motor proficiency results of all children with ADHD irrespective of age.

Almost all studies included participants of both sexes except one, which included only boys. ${ }^{10)}$ Fewer girls than boys were included in the studies, and none of the studies reported sexbased differences in the motor performance of children with 
ADHD. No studies compared the motor performance of typically developing versus $\mathrm{ADHD}$ group girls.

\section{Sample size}

The sample sizes of the included studies varied by study design, with observational studies recruiting a greater number of participants than interventional studies. Overall, fewer female than male participants were included.

\section{Children other than ADHD}

Few studies compared the motor abilities of children with ADHD with those of children with other developmental and behavioral disorders such as DBD, ODD, CD $,{ }^{10)} \mathrm{ASD}, \mathrm{DCD},{ }^{11)}$ and $\mathrm{RD}^{12,18)}$ and typically developing children. ${ }^{14)}$ Another study assessed cognitive and motor abilities of children with ADHD with children with RD. ${ }^{12,18)}$ All studies reported that children with ADHD showed better motor performance than children with other behavioral disorders but not when compared with typically developing children. ${ }^{10-12,14)}$ Moreover, motor impairment in $\mathrm{ADHD}$ increased as a function of co-occurring disorders. ${ }^{14)}$

Studies that recruited children with ADHD who were under medicines ensured that children with ADHD were not on stimulant medications at least 2-3 days before administering the BOTMP to avoid any risk of bias on motor performance of participants. ${ }^{4,10,11,13-16,19)}$

\section{ADHD type}

Most studies did not mention ADHD type of the children that they recruited. According to DSM criteria, children with ADHD are classified into the following subtypes: ADHD-I (impulsive), ADHD-H (hyperactive), and ADHD-C (combined). ${ }^{16)}$ Three studies specifically mentioned including children with ADHD type $\mathrm{C}$, while the remaining 11 studies included children diag. nosed with $\mathrm{ADHD}$ without specifying type., ${ }^{4,8-17)}$

\section{Study designs}

None of the included studies blinded the assessors or children before conducting the test; however, some randomly allocated the children into groups and blinded the parents, assessors, and participants. Some studies blinded only the study participants, 5 , 12,14,17) whereas other studies blinded only the assessors. ${ }^{11,12,17)}$ Studies also mentioned that all assessors were experienced in conducting BOTMP tests, which took 45-60 minutes to complete. $5,8-12,15-17)$

The RCT compared the motor proficiencies of children with ADHD pre- and postintervention with methylphenidate $(0.25$, $0.5,1 \mathrm{mg} / \mathrm{kg} /$ day) and showed better motor performance after 1 week of treatment. An intervention study that compared the effect of cognitive intervention for 12 weeks resulted in greater improvement in the functional abilities of participants postintervention. . $^{\text {) }}$

A cross-sectional observational study that used the balance component mentioned that children with ADHD type $\mathrm{C}$ had less consistent movement patterns and that the static and dynamic balance ability skill levels in ADHD group were not as high as those in the control group. ${ }^{15)}$ Another cross-sectional observational study that compared the motor performance of ADHD type $\mathrm{I}, \mathrm{ADHD}$ type $\mathrm{H}$, and $\mathrm{ADHD}$ type $\mathrm{C}$ with age- and sexmatched controls found differences in dynamic hand coordination between controls and children with ADHD type $\mathrm{C}$, dynamic general coordination between controls and $\mathrm{ADHD}$ type $\mathrm{H}$, and in frequency of synkinetic movements between controls and children with ADHD type $\mathrm{H}$. Children with $\mathrm{ADHD}$ and severe hyperactivity showed a greater frequency of motor alterations. ${ }^{16)}$

Another interventional study assessed children with ADHD 5 times using BOT-2 SF during a 32-week equine-assisted activity and brain-building program and reported significant impro-

Table 3. NIH quality assessment of studies

\begin{tabular}{|c|c|c|c|c|c|c|c|c|c|c|c|c|c|c|}
\hline \multirow{2}{*}{ Study designs } & \multicolumn{14}{|c|}{ Questions } \\
\hline & Q1 & Q2 & Q3 & Q4 & Q5 & Q6 & Q7 & Q8 & Q9 & Q10 & Q 11 & Q 12 & Q13 & Q 14 \\
\hline Rigby et al., ${ }^{17)} 2020$ & $Y$ & $Y$ & Y & $Y$ & $\mathrm{~N}$ & $\mathrm{Y}$ & $Y$ & $\mathrm{~N}$ & $Y$ & Y & $\mathrm{N}$ & Y & - & - \\
\hline Mancini et al., ${ }^{15)} 2020$ & Y & $\mathrm{N}$ & Y & $\mathrm{N}$ & $\mathrm{N}$ & $\mathrm{N}$ & $\mathrm{N}$ & NA & Y & $\mathrm{N}$ & Y & $\mathrm{N}$ & Y & $\mathrm{N}$ \\
\hline Cak et al., 2018 & Y & Y & Y & Y & $\mathrm{N}$ & $\mathrm{N}$ & $\mathrm{N}$ & NA & Y & $\mathrm{N}$ & Y & Y & Y & $\mathrm{N}$ \\
\hline Damme et al., 2015 & Y & Y & Y & $\mathrm{N}$ & $\mathrm{N}$ & $\mathrm{N}$ & $\mathrm{N}$ & NA & $\mathrm{N}$ & $\mathrm{N}$ & Y & $\mathrm{N}$ & Y & $\mathrm{N}$ \\
\hline Mao et al., ${ }^{7)} 2014$ & Y & Y & Y & Y & $\mathrm{N}$ & $\mathrm{N}$ & $\mathrm{N}$ & NA & $\mathrm{N}$ & $\mathrm{N}$ & Y & $\mathrm{N}$ & Y & $\mathrm{N}$ \\
\hline Poblano et al., 2014 & Y & Y & Y & Y & $\mathrm{N}$ & $\mathrm{N}$ & $\mathrm{N}$ & NA & $\mathrm{N}$ & $\mathrm{N}$ & Y & $\mathrm{N}$ & Y & $\mathrm{N}$ \\
\hline Cho et al., 2013 & Y & Y & Y & Y & $\mathrm{N}$ & $\mathrm{N}$ & $\mathrm{N}$ & NA & $\mathrm{N}$ & $\mathrm{N}$ & Y & $\mathrm{N}$ & Y & $\mathrm{N}$ \\
\hline Dewey et al., ${ }^{11)} 2007$ & Y & Y & Y & Y & $\mathrm{N}$ & $\mathrm{N}$ & $\mathrm{N}$ & NA & $\mathrm{N}$ & $\mathrm{N}$ & Y & Y & Y & Y \\
\hline Kooistra et al., 2005 & Y & Y & Y & $\mathrm{N}$ & Y & $\mathrm{N}$ & $\mathrm{N}$ & NA & $\mathrm{N}$ & $\mathrm{N}$ & Y & Y & Y & $\mathrm{N}$ \\
\hline Tseng et al., ${ }^{27)} 2004$ & Y & Y & Y & Y & $\mathrm{N}$ & $\mathrm{N}$ & $\mathrm{N}$ & NA & $\mathrm{N}$ & $\mathrm{N}$ & Y & $\mathrm{N}$ & Y & Y \\
\hline Dewey et al., 2003 & Y & Y & Y & Y & Y & $\mathrm{N}$ & $\mathrm{N}$ & NA & $\mathrm{N}$ & $\mathrm{N}$ & Y & Y & Y & Y \\
\hline Jang et al., ${ }^{14)} 2015^{a)}$ & Y & Y & Y & Y & $\mathrm{N}$ & Y & Y & Y & Y & Y & Y & Y & - & - \\
\hline Gharebaghy et al., ${ }^{1)} 2014^{\mathrm{a})}$ & Y & Y & Y & Y & $\mathrm{N}$ & Y & Y & Y & Y & Y & $\mathrm{N}$ & NA & - & - \\
\hline Soleimani et al., ${ }^{22)} 2017^{\text {a) }}$ & Y & Y & Y & Y & Y & Y & Y & Y & Y & $\mathrm{N}$ & Y & $N$ & Y & $\mathrm{N}$ \\
\hline
\end{tabular}

$\mathrm{NIH}$, National Heart, Lung, and Blood Institute; Y, yes; N, no; NA, not applicable.

a) Interventional study. 
vement in the subtest scores of manual dexterity, upper limb coordination, and strength. ${ }^{20)}$

\section{Use of ВОтМР/Вот-2}

Most of the studies that used the BOTMP as their outcome measure preferred using the LF version (Table 4). Two studies used the BOT-2 SF because of time constraints, ${ }^{17,20)}$ and other studies used the BOTMP SF. ${ }^{12,18)}$ A study used the LF and SF of the BOT-2, ${ }^{4)}$ while a few studies used only the BOT-2 LF, ${ }^{9,10,13)}$ few other studies used the BOTMP LF, 2,5,8,14,16,19) and one used only the balance subtest of the BOTMP. ${ }^{15)}$

The motor performance of children with ADHD varied across regions where the study was performed. Children from regions of Iran and Korea showed lower performance on motor skills domains than children from regions of Canada, Turkey, and Taiwan (Table 5). 5,8,11,13-15,17,19) According to the total motor composite scores, children with ADHD from one part of Australia displayed lower motor performance than children with ADHD from another part of Australia (Table 5). ${ }^{11)}$

Few studies used other motor assessment tools along with

\section{Table 4. Included studies by assessment tool}

\begin{tabular}{|c|c|c|}
\hline Study & Year & ВОТМР/ВОТ-2 \\
\hline Rigby et al., ${ }^{17)} 2020$ & 2020 & BOT-2 SF \\
\hline Mancini et al., ${ }^{15)} 2020$ & 2019 & BOT-2 LF AND SF \\
\hline Cak et al., 2018 & 2018 & BOTMP LF \\
\hline Soleimani et al., ${ }^{22)} 2017$ & 2017 & BOT-2 SF \\
\hline Damme et al., ${ }^{10)} 2015$ & 2015 & BOT-2 LF \\
\hline Jang et al., ${ }^{14)} 2015$ & 2015 & BOT-2 LF \\
\hline Mao et al., 2014 & 2014 & BOTMP BALANCE SUBTEST \\
\hline Poblano et al., ${ }^{20)} 2014$ & 2014 & BOTMP LF \\
\hline Gharebaghy et al., ${ }^{1)} 2014$ & 2014 & BOTMP LF \\
\hline Cho et al., ${ }^{9)} 2013$ & 2013 & BOT-2 LF \\
\hline Dewey et al., ${ }^{11)} 2007$ & 2007 & BOTMP SF \\
\hline Kooistra et al., ${ }^{2)} 2005$ & 2005 & BOTMP LF \\
\hline Tseng et al., ${ }^{27)} 2004$ & 2004 & BOTMP LF \\
\hline Dewey et al., ${ }^{18)} 2003$ & 2003 & BOTMP SF \\
\hline
\end{tabular}

BOTMP, Bruininks-Oseretsky Test of Motor Proficiency; BOT-2, BruininksOseretsky Test of Motor Proficiency Second Edition; LF, long form; SF, short form.

Table 5. Total motor composite scores of children with ADHD

\begin{tabular}{|c|c|c|}
\hline \multirow{2}{*}{ Study } & \multicolumn{2}{|c|}{ BOTMP/BOT-2 motor composite score } \\
\hline & Mean $\pm S D$ & Median (IQR) \\
\hline Mancini et al., ${ }^{15)} 2020$ & $40.55 \pm 8.55$ & - \\
\hline Cak et al., ${ }^{8)} 2018$ & - & $52(36-70)$ \\
\hline Jang et al., ${ }^{14)} 2015$ & $40.53 \pm 6.83$ & - \\
\hline Cho et al., ${ }^{9)} 2013$ & $43.12 \pm 8.37$ & - \\
\hline Dewey et al., 2007 & $59.80 \pm 1.20$ & - \\
\hline Kooistra et al., $\left.{ }^{2}\right) 2005$ & $51.90 \pm 8.40$ & - \\
\hline Tseng et al.,. ${ }^{27)} 2004$ & $52.62 \pm 12.69$ & - \\
\hline Dewey et al., ${ }^{18)} 2003$ & $55.58 \pm 10.99$ & - \\
\hline
\end{tabular}

ADHD, attention deficit hyperactivity disorder; BOTMP, Bruininks-Oseretsky Test of Motor Proficiency; BOT-2, Bruininks-Oseretsky Test of Motor Proficiency Second Edition; SD, standard deviation; IQR, interquartile range. the BOTMP. Another used the MABC to compare the balance of typically developing children with that of children with ADHD and reported similar performances across both tools, with typically developing children performing better than those with ADHD. ${ }^{15)}$ Another study used the Canadian Occupational Performance Measure and the BOTMP to assess goal-oriented motor performance (cognitive orientation and daily occupational performance) before and after intervention in children with ADHD. ${ }^{5)}$

\section{Tool administration}

The tool was administered by different professionals according to the guidelines of each. ${ }^{21)}$ All studies had assessors from varied medical backgrounds administering the tool, i.e., occupational therapists, ${ }^{12,13,14,18,19)}$ physical therapists, ${ }^{14,19)}$ psychiatric therapists, ${ }^{12)}$ and a psychomotor therapist. ${ }^{10)}$ Some of the studies did not specify who administered the tool.

\section{Motor composite scores of children with ADHD}

Motor composite score is the total score of all activities assessed by the BOTMP tool. ${ }^{6}$ ) The normal range is within confidence interval of 40\%-60\% ${ }^{8)}$ Children with scores beyond this range are categorized at risk of having motor impairments. ${ }^{8}$ The motor composite scores of various studies of children with ADHD (Table 5) were 40.55-59.8, which implies that there were varying levels of motor performance of children with $\mathrm{ADHD}$ in the different regions. As all studies utilized the LF or SF of the BOTMP or BOT-2, motor composite scores varied, while most studies did not mention motor composite scores. ${ }^{4,8,9,11-15,17,19)} \mathrm{A}$ few studies reported a low motor performance of children with $\mathrm{ADHD},{ }^{4,9,13,17)}$ while the other studies reported better motor performance of children with ADHD. . $^{811,12,14,19)}$

\section{Discussion}

This literature review examined the extent of BOTMP used in studies of children with ADHD. We aimed to methodically compile the extent of BOTMP usage in children with ADHD by exploring various aspects like countries in which the tool was administered, various set-ups in which it was used, the motor performance of children with ADHD according to the tool, and qualification of people eligible to administer the tool.

\section{Tools assessing motor proficiency in children with ADHD}

A study that used the MABC to assess balance reported the same performance of children with ADHD. This study did not mention the reason it used 2 motor assessment tools. ${ }^{15)}$ Contrary to other motor skill tests, such as the BOTMP, which measures a child's strengths and weaknesses over a wide range of skills, the $\mathrm{MABC}$ is restricted to movement skills of a specific age range. $\left.{ }^{6}\right)$

The BOTMP has a few tests with time limits, a few that demand physical exercise and strength, and a few that demand concentration on the task completion for a short time span. This 
demands the child to accommodate their cognitive level, agility, and concentration per the exercise or task performed. This will be challenging for children with $\mathrm{ADHD}$ as they will have to focus appropriately to perform to the best of their ability, which might not be the case for other tools. BOTMP also offers practice and repeated trials, giving them a chance for improvement in subsequent trial. These features enhanced the tool's usage in children with neurodevelopmental disorders, especially those with ADHD.

The preference of BOTMP for assessing the motor proficiency of children with ADHD could be due to its wider age range and thorough applicability of subtests in all areas of childhood neurological developmental disorders. Knowing the ADHD nature of these children, they thoroughly enjoyed the BOTMP assessment process. Moreover, the individual raw and total subtest scores provided a thorough clinical representation of their motor deficits, which helps therapists plan effective treatment strategies.

\section{BOTMP/BOT-2}

The BOTMP has good inter-rater reliability (0.92-0.99), moderate test retest reliability (0.69-0.8), moderate construct validity $(0.56-0.86)$, and moderate criterion validity $(0.45-$ $0.75) .{ }^{6}$ The tool had 46 test items and was upgraded to BOT2 , having 53 test items. The BOT-2 has 8 subtests that cover all areas of motor development; fine motor precision (7 items), fine motor integration (8 items), manual dexterity (5 items), bilateral coordination (7 items), balance (9 items), running speed and agility (5 items), upper limb coordination (7 items), and strength (5 items). ${ }^{6}$

The tool has been standardized only in the United States, ${ }^{6}$ one province of Canada, ${ }^{6}$ and Hong Kong. ${ }^{6)}$ Moreover, it has also been translated into regional languages in Iran, Turkey, Spain, and others. ${ }^{6,20)}$

\section{Quality assessment of the included studies}

Of the 14 studies, 8 had a fair score that did not consider the effect of confounding variables on the results and did not elaborate on how sample size was calculated; they simply stated their sample size and grades (Table 2). One study showed poor performance on the quality analysis because it lost points for not reporting the study's power; it did not mention all of the details about estimates of random variability in the data for main outcomes and did not clearly mention the main study findings. Overall, the quality of the included studies was fair, which was primarily attributed to the missing details.

\section{Characteristics of the included studies}

The BOTMP was used to assess various conditions such as $\mathrm{ADHD}, \mathrm{DCD},{ }^{11,17)}$ disruptive behavior disorder, ${ }^{10)} \mathrm{ASD},{ }^{11,20)}$ $\mathrm{RD},{ }^{12,14,18)}$ and ODD. ${ }^{12)}$

The tool has been used across both observational and interventional studies. Observational studies used it at one point in time, while intervention studies used it multiple times. ${ }^{4,8,10,12,14-16,19)}$ It was used twice in one of the intervention studies to assess the differences between pre- and postintervention changes on the motor performance of children with ADHD. ${ }^{13)}$ One of the intervention studies reported using it 6 times over the intervention phase to track changes in motor performance weekly postintervention. ${ }^{5)}$ Another study used the SF of the tool 5 times during the 32-week intervention to track changes in motor performance. ${ }^{20)}$ The RCT reported having assessed motor performance thrice using the tool (at baseline, during the trial phase, and post-trial). ${ }^{17)}$

\section{Age and sex}

Children at least 6-7 years old were included in almost all of the studies. The reasons for including children of this age could be their active involvement in outdoor activities. Children develop an interest in outdoor play and skillful motor activities around 6-7 years of age when they start exploring sports and motor activities. One study recruited children with an age of 5 years. ${ }^{8)}$ Children less than 6 years of age usually do not display efficient motor skills unless genetically inherited. Overall, more boys than girls were recruited in all studies. ${ }^{4,5,8-16,19,20)}$ According to the DSM-IV, the male to female ratio of children with ADHD is 2:1 and $3: 1^{, 7)}$ but it decreases in adolescents and adults with ADHD. Sex and age differences in children with ADHD occurred more often in ADHD subtypes. ${ }^{7)}$ Moreover, lower male to female ratios could be attributed to the underdiagnosis of females with ADHD.7)

\section{Use of BOTMP in studies}

We came across one study that used only a single subtest of BOTMP. ${ }^{15)}$ Some studies used motor composites of fine manual control and manual coordination more than other motor composites. ${ }^{2)}$ The body coordination motor composite was used comparatively more than the strength and agility motor com. posite, whereas the balance subtest of the tool was used more than the other subtests. ${ }^{1)}$ This could be because most of the children with ADHD are ambulatory, and because of their underlying structural changes in the brain, they have balance and incoordination issues that lead to more extensive use of the BOTMP balance subtest.

Neither of the studies reported any barriers with the test administration. The assessors were thorough with the subtests, and it was fun for the child to perform the test and for the assessor to administer it. ${ }^{4,11,12)}$

\section{Use of the tool's SF and LF}

The included studies used the BOTMP in various forms, i.e. the SF, LF, or subtests (Table 4). The SF was created by adding a few tests from all motor composites of the LF to save time during administration. ${ }^{6}$ ) The main purpose of the tool was to screen the children's motor abilities. However, the SF of the tool is reportedly not as efficient as the LF in terms of validity and reliability. $\left.{ }^{6}\right)$

Unlike the SF, the LF of the BOTMP assesses the overall motor proficiency of children. The longer administration time of an hour was the only drawback of the LF.') However, this duration 
gradually decreased as the therapists became more acquainted with the sequence of the subtests. ${ }^{5)}$ Studies that used the LF of the tool reported a lower motor composite score than what was reported by studies using the SF, which was specifically developed for screening purposes. ${ }^{6}$ The BOTMP is a paid tool, making it not easily accessible for many.

Observational studies that used the tool to assess the motor abilities of children with ADHD preferred using the LF. Some studies mentioned their reasoning for using the LF as it performing a thorough neurodevelopmental assessment of all specific fine and gross motor activities and gave a clear picture of specific motor impairment unlike the SF, which assessed only selected fine and gross motor tests. ${ }^{4,12,15)}$

\section{Motor performance of ADHD versus other behavioral disorders}

Few studies that compared the motor abilities of children with ADHD, children with other behavioral disorders, and typically developing children concluded that the motor abilities of children with $\mathrm{ADHD}$ were lower than those of typically developing children and higher than those of children with other behavioral disorders. This finding, however, cannot be generalized as the study only assessed children with an intelligence quotient greater than 70-80. 8,10-12-14,16,17)

Few studies reported that children with DCD had lower motor proficiency than children with ADHD. ${ }^{11,17)}$ DCD and $\mathrm{ADHD}$ are neurodevelopmental disorders with unclear intrinsic pathological differences. DCD comprises impairments in cognition and coordination, which explains the low motor performance of children with DCD, while children with ADHD have primary motor planning and execution impairments. ${ }^{3)}$ Another study comparing children with ODD and RD and children with ADHD reported that the latter performed better than the other groups. ${ }^{22)}$

Almost all the studies that compared the motor abilities of children with ADHD and typically developing children mentioned that, although the motor abilities of ADHD children were not as good as those of typically developing children, the motor abilities of children with ADHD could improve with appropriate interventions. $5,8,9,11,12,14-17)$

Children from different cultures reportedly develop at different rates; thus, the application of a set of norms to children belonging to varied cultural backgrounds might lead to a false interpretation of their motor abilities. As shown in Table 5, children with $\mathrm{ADHD}$ displayed varied motor performances depending on culture and region. The observed variations in motor performance in various regions could have many possible reasons such as variations in nutrition, genetics, ethnicity, overall development and care, environmental factors, cultural practices, ADHD type, and rehabilitation. ${ }^{17)}$

Overall, according to studies of the application of the BOTMP among children with $\mathrm{ADHD}$, the tool has been used in various countries, translated into various regional languages, and used in variants of $\mathrm{ADHD}$ with a wide range of age groups administered by various qualified medical and para-medical professionals.
Many studies preferred using the LF of the BOTMP or the BOT2 over the SF for children with ADHD.

\section{Strengths of the study}

This is one of the first studies to review the use of the BOTMP for evaluating motor performance in children with ADHD. This review provided extensive information about how the tool has been used to assess the motor impairments of children with ADHD. The study compiled use of the BOTMP tool in various countries, its cultural adaptations, level of motor performances displayed by children with ADHD in various regions, and usage of different versions of the tool e.g., BOTMP/BOT-2 and LF/SF.

\section{Limitations}

Since studies published only in English were searched, studies published in other languages could have been missed. The quality of most of the included studies was fair, which implies the need to use stringent methodologies. A meta-analysis was out of the scope of this review due to the differences in study designs and the fact that all of the studies used different versions of the tool i.e., SF, LF, or subtest of the BOTMP or the BOT-2. The studies also did not categorize motor composite scores according to age group, sex, or ADHD variant, i.e., ADHD-I, ADHD-H, or ADHD-C.

\section{Future recommendations}

Further research is required to understand the motor repertoire of children with ADHD using the BOTMP. There is scope for understanding and analyzing the motor abilities of children with ADHD-H, ADHD-I, or ADHD-C. Further, the motor composite scores of children must be analyzed based on their age, sex, and ADHD variant, as this information will help improve our understanding of the condition and aid in planning future interventions. Due to the influence of culture on motor development, cultural adaptations of the tool in various countries are recommended.

\section{Conclusion}

Although used globally, the BOTMP has been used sparsely as an outcome measure to understand the motor performance of children with ADHD. The motor capabilities of children with ADHD remain unclear due to the predisposition of other behavioral disorders. Categorizing motor performances according to age and sex might help increase our understanding of their motor abilities to aid in their rehabilitation.

\section{Footnotes}

Supplementary material: Supplementary Table 1 can be found via https://doi.org/10.3345/cep.2021.00962. 
Conflicts of interest: No potential conflict of interest relevant to this article was reported.

Funding: This study received no specific grant from any funding agency in the public, commercial, or not-for-profit sectors.

\section{ORCID:}

Suruliraj Karthikbabu (1) https://orcid.org/0000-0002-7513-0606

Pratiksha Tilak Rao @ https://orcid.org/0000-0001-5760-2676

Author Contribution: Conceptualization: PTR, SK, KPA; Data curation: KPA; Formal analysis: KPA; Funding acquisition: None; Methodology: PTR, SK, KPA; Project administration: PTR, SK, KPA; Visualization: PTR, SK, KPA; Writing - original draft: KPA, PTR; Writing - review \& editing: PTR, SK, KPA

\section{References}

1. Gharebaghy S, Rassafiani M, Cameron D. Effect of cognitive intervention on children with ADHD. Phys Occup Ther Pediatr 2014;35:13-23.

2. Kooistra L, Crawford S, Dewey D, Cantell M, Kaplan BJ. Motor correlates of ADHD: contribution of reading disability and oppositional defiant disorder. J Learn Disabil 2005;38:195-206.

3. Goulardins JB, Marques JC, De Oliveira JA. Attention deficit hyperactivity disorder and motor impairment. Percept Mot Skills 2017;124:425-40.

4. Kaiser ML, Schoemaker MM, Albaret JM, Geuze RH. What is the evidence of impaired motor skills and motor control among children with attention deficit hyperactivity disorder (ADHD)? Systematic review of the literature. Res Dev Disabil 2015;36:336-57.

5. Fliers E, Rommelse N, Vermeulen SH, Altink M, Buschgens CJ, Faraone $\mathrm{SV}$, et al. Motor coordination problems in children and adolescents with ADHD rated by parents and teachers: effects of age and gender. J Neural Transm 2008;115:211-20.

6. Cools W, Martelaer KD, Samaey C, Andries C. Movement skill assessment of typically developing preschool children: a review of seven movement skill assessment tools. J Sports Sci Med 2009;8:154-68.

7. Mao HY, Kuo LC, Yang AL, Su CT. Balance in children with attention deficit hyperactivity disorder-combined type. Res Dev Disabil 2014;35: 1252-8.

8. Cak HT, Karaokur R, Atasavun Uysal S, Artik A, Yildiz Kabak V, Karakok $\mathrm{B}$, et al. Motor proficiency in children with attention deficit hyperactive disorder: associations with cognitive skills and symptom severity. Turk Psikiatri Derg 2018;29:1-10.

9. Cho H, Ji S, Chung S, Kim M, Joung YS. Motor function in school-aged children with attention-deficit/hyperactivity disorder in Korea. Psychiatry Investig 2014;11:223-7.

10. Van Damme T, Sabbe B, van West D, Simons J. Motor abilities of adolescents with a disruptive behaviour disorder: the role of comorbidity with ADHD. Res Dev Disabil 2015;40:1-10.

11. Dewey D, Cantell M, Crawford SG. Motor and gestural performance in children with autism spectrum disorders, developmental coordination disorder and/or attention deficit hyperactivity disorder. Motor Gest Perform 2007; 13:246-56.

12. Dewey D, Crawford SG, Kaplan BJ. Clinical importance of parent ratings of everyday cognitive abilities in children with learning and attention problems. J Learn Disabil 2015;36:87-95.

13. Goulardins JB, Rigoli D, Licari M, Piek JP, Hasue RH, Oosterlaan J, et al. Attention deficit hyperactivity disorder and developmental co-ordination disorder: two separate disorders or do they share a common etiology. Behav Brain Res 2015;292:484-92.
14. Jang B, Song J, Kim J, Kim S, Lee J, Shin HY, et al. Equine-assisted activities and therapy for treating children with attention-deficit/hyperactivity disorder. J Altern Complement Med 2015;21:546-53.

15. Mancini V, Rudaizky D, Howlett S, Elizabeth-Price J, Chen W. Movement difficulties in children with ADHD: comparing the long and short form Bruininks-Oseretsky Test of Motor Proficiency-Second Edition (BOT-2). Aust Occup Ther J 2020;67:153-61.

16. Suarez-Manzano S, Ruiz-Ariza A, De La Torre-Cruz M, Martinez-Lopez EJ. Acute and chronic effect of physical activity on cognition and behaviour in young people with ADHD: a systematic review of intervention studies. Res Dev Disabil 2018;77:12-23.

17. Rigby BR, Davis RW, Bittner MD, Harwell RW, Leek EJ, Johnson GA, et al. Changes in motor skill proficiency after equine-assisted activities and brain-building tasks in youth with neurodevelopmental disorders. Frontier Vet Sci 2020;7:22.

18. Dewey D, Crawford SG, Kaplan BJ. Clinical importance of parent ratings of everyday cognitive abilities in children with learning and attention problems. J Learn Disabil 2003;36:87-95.

19. Schneider E, Parush S, Katz N, Miller LJ. Performance of Israeli versus U.S. preschool children on the Miller Assessment for preschoolers. Am J Occup Ther 1995;49:19-23.

20. Poblano A, Luna B, Reynoso C. Differential motor alterations in children with three types of attention deficit hyperactivity disorder. Arq Neuropsiquiatr 2010;72:856-61.

21. Bruininks R, Bruininks B. Bruininks-Oseretsky Test of Motor Proficiency. 2nd ed. Circle Pines (MN): American Guidance Service, 2005.

22. Soleimani R, Kousha M, Zarrabi H, Tavafzadeh-Haghi SM, Jalali MM. The impact of methylphenidate on motor performance in children with both attention deficit hyperactivity disorder and developmental coordination disorder: a randomized double-blind crossover clinical trial. Iran J Med 2017;42:354-61.

23. Ramtekkar UP, Reiersen AM, Todorov AA, Todd RD. Sex and age differences in attention-deficit/hyperactivity disorder symptoms and diagnoses: implications for DSM-V and ICD-11. J Am Acad Child Adolesc Psychiatry 2010;49:217-28.

24. Chui M, Ng A, Fong A, Lin L, Ng M. Differences in fine motor performance of children in Hong Kong and the United States on the BruininksOseretsksy test of motor proficiency. Hong Kong J Occup Ther 2007; 17: $1-9$.

25. Catherine TG, Robert NG, Mala KK, Kanniammal C, Arullapan J. Assessment of prevalence of attention deficit hyperactivity disorder among school children in selected schools. Indian J Psychiatry 2019;61:232-7.

26. Taurines R, Schmitt J, Renner T, Conner AC, Warnke A, Romanos M. Developmental comorbidity with attention-deficit/hyperactivity disorder. Atten Def Hype Disord 2010;2:267-89.

27. Tseng MH, Henderson A, Chow SM, Yao G. Relationship between motor proficiency, attention, impulse and activity in children with ADHD. Dev Med Child Neurol 2004;46:381-8.

28. Tuvblad C, Zheng M, Raine A, Baker LA. A common genetic factor explains the covariation among ADHD ODD and $\mathrm{CD}$ symptoms in 9-10 year old boys and girls. J Abnorm Child Psychol 2009;37:153-67.

29. Venetsanou F, Kambas A, Aggeloussis N, Serbezis V, Taxildaris K. Use of the Bruininks-Oseretsky Test of Motor Proficiency for identifying children with motor impairment. Dev Med Child Neurol 2007;49:846-8.

30. Willcutt EG. The prevalence of DSM-IV attention-deficit/hyperactivity disorder: a meta-analytic review. Neurotherapeutics 2012;9:490-9.

How to cite this article: Adhvaryu KP, Karthikbabu S, Rao PT. Motor performance of children with attention deficit disorder with hyperactivity: focus on the Bruininks-Oseretsky Test of Motor Proficiency. Clin Exp Pediatr 2022;65:512-20. https:// doi.org/10.3345/cep.2021.00962 